\title{
Physician Burnout and Higher Clinic Capacity to Address Patients' Social Needs
}

\author{
Emilia De Marchis, MD, Margae Knox, MPH, Danielle Hessler, PhD, \\ Rachel Willard-Grace, MPH, J. Nwando Olayiwola, MD, MPH, \\ Lars E. Peterson, MD, PhD, Kevin Grumbach, MD, and Laura M. Gottlieb, MD, MPH
}

Background: A recent regional study found lower burnout among primary care clinicians who perceived that their clinic had greater capacity to meet patients' social needs. We aimed to more comprehensively investigate the association between clinic capacity to address social needs and burnout by using national data that included a more representative sample of family physicians and a more comprehensive set of practice-level variables that are potential confounders of an association between clinic social needs capacity and burnout.

Methods: We conducted a cross-sectional analysis of 1298 family physicians in ambulatory primary care settings who applied to continue certification with the American Board of Family Medicine in 2016. Logistic regression was used to test associations between physician and clinic characteristics, perceived clinic social needs capacity, and burnout.

Results: A total of $27 \%$ of family physicians reported burnout. Physicians with a high perception of their clinic's ability to meet patients' social needs were less likely to report burnout (adjusted odds ratio $[\mathrm{OR}], 0.66 ; 95 \%$ confidence interval $[\mathrm{CI}], 0.47-0.91)$. Physicians who reported high clinic capacity to address patients' social needs were more likely to report having a social worker (adjusted OR, 2.16; 95\% CI, 1.44-3.26) or pharmacist (adjusted OR, 1.73; 95\% CI, 1.18-2.53) on their care team and working in a patient-centered medical home (adjusted OR, 1.65; 95\% CI, 1.24-2.21).

Conclusion: Efforts to reduce primary care physician burnout may be furthered by addressing structural issues, such as improving capacity to respond to patients' social needs in addition to targeting other modifiable burnout risks. (J Am Board Fam Med 2019;32:69-78.)

Keywords: Family Physicians, Patient-Centered Care, Primary Health Care, Professional Burnout

In light of a growing recognition that clinician well-being is a foundational component of a highfunctioning health care system, ${ }^{1,2}$ it is alarming that more than $60 \%$ of US family physicians report

This article was externally peer reviewed.

Submitted 4 April 2018; revised 13 June 2018; accepted 15 June 2018.

From Department of Family \& Community Medicine, University of California San Francisco, San Francisco (ED, DH, JNO, LMG), Center for Excellence in Primary Care, Department of Family \& Community Medicine, University of California San Francisco, San Francisco (MK, RW-G, KG), American Board of Family Medicine, Lexington, KY (LEP).

Funding: This publication was supported by the Hellman Family Foundation UCSF FY 2015-16 and a fellowship training grant by the National Research Service Award (NRSA) T32HP19025. Its contents are solely the responsibility of the authors and do not represent the official views of the Hellman Family Foundation or NRSA.

Conflict of interest: none declared. symptoms of burnout. ${ }^{3}$ A new body of research has emerged exploring both clinician- and practicelevel risk factors for burnout as potential targets for intervention. Reported clinician-level burnout risk factors include being midcareer ${ }^{4}$, spending a higher percent time in clinical activities ${ }^{5,6}$, and being female. ${ }^{7,8}$ Reported practice-level burnout risk factors include electronic health record (EHR) bur$\operatorname{den}^{9,10}$, work stress, poor team efficiency ${ }^{6,9,10-12}$, and poor or misaligned clinical leadership. ${ }^{9,12,13}$

Burnout is of particular concern in United States safety-net practices, where the level of need frequently exceeds available resources. ${ }^{14-17}$ In these

Corresponding author: Emilia De Marchis, MD, Department of Family \& Community Medicine, University of California, San Francisco, 1001 Potrero Ave, Ward 83, San Francisco, CA 94110 (E-mail: emilia.demarchis@ucsf.edu). 
settings, one study with a relatively small sample size suggested that risk factors for burnout extend beyond common clinician and practice variables associated with burnout to include insufficient organizational resources to address patients' social needs. ${ }^{18}$ This association between clinic capacity to address social needs and clinician burnout has not been examined in large, representative samples of physicians.

The current study leverages survey data from a national sample of family physicians from diverse settings applying to the American Board of Family Medicine (ABFM) to continue their specialty certification. The study goals were to (1) better understand the associations between burnout, clinic capacity to address patients' social needs, and other burnout risk factors; and (2) to identify practicelevel factors associated with clinic capacity to address patients' social needs. We hypothesized that physicians who did not perceive that their clinic was equipped to meet the social needs of their patients would have higher burnout and that the inverse relationship between social needs capacity and burnout would be stronger for physicians working in safety-net settings.

\section{Methods}

Survey data are from the 2016 ABFM Family Medicine Certification practice demographic questionnaire. The questionnaire is a mandatory component of examination registration, which occurs 3 to 4 months before the examination date. In the 2016 ABFM continuing certification process, all applicants completed a core set of questions, which included a measure of physicians' perception of their clinic's capacity to address patients' social needs. Applicants were also randomized to 1 of 5 modules, 1 of which included measures of burnout and burnout risk factors. The study was reviewed by the University of California San Francisco Institutional Review Board and deemed not human subjects research (15-18360).

\section{Study Sample}

Of the 9658 physicians applying to continue their certification (survey response rate 100\%), 1925 were randomly administered the burnout module. We then excluded burnout module respondents if their primary worksite was not either a freestanding ambulatory care clinic or a hospital-based clinic $(\mathrm{n}=542)$; if they reported having less than 1 year of clinical practice experience $(\mathrm{n}=11)$; or if they reported not having an EHR and, therefore, were not offered the burnout module questions on EHR use $(n=74)$. After these exclusions, 1298 participants were included in the study sample.

\section{Measures \\ Self-Reported Burnout \\ The primary burnout outcome was measured using a validated, single-item question asking physicians to rate their level of burnout (1 to 5 scale) (Table 1). ${ }^{19}$ As has been done in earlier studies, ${ }^{20}$ we di- chotomized the burnout measure so that reporting no symptoms of burnout or stress was considered "not burned out" (score 1 or 2), whereas reporting greater than 1 symptom of burnout was considered "burned out" (score $\geq 3$ ).}

\section{Perceived Clinic Capacity to Address Patients' Social Needs} The primary predictor variable was a single-item measure of physician-reported clinic capacity to

Table 1. Single-Item Burnout Question and Response Options from the 2016 American Board of Family Medicine Certification Practice Demographic Questionnaire, Dichotomized to Indicate Primary Reported Outcome of Burnout Versus Not Burned Out

\begin{tabular}{ll}
\hline Question Stem & Using Your Own Definition of Burnout, Select an Answer: \\
\hline $\begin{array}{l}\text { Responses Classified as Not Burned } \\
\text { Out }\end{array}$ & $\begin{array}{l}\text { 1. I enjoy my work. I have no symptoms of burnout. } \\
\text { 2. I am under stress, and don't always have as much energy as I did, but I don't feel } \\
\text { burned out. }\end{array}$ \\
$\begin{array}{ll}\text { Responses Classified as Burned Out } \\
\text { emotional exhaustion. }\end{array}$ \\
$\begin{array}{ll}\text { 4. The symptoms of burnout that I'm experiencing won't go away. I think about } \\
\text { work frustrations a lot. }\end{array}$ \\
\begin{tabular}{l} 
5. I feel completely burned out. I am at the point where I may need to seek help. \\
\hline
\end{tabular}
\end{tabular}


address patients' social needs (clinic social determinants of health $[\mathrm{SDH}]$ capacity). This measure was used in a prior study of primary care clinicians and found to have both high face- and content-validity. ${ }^{18}$ The question read: "My clinic has the resources, such as dedicated staff, community programs, resources or tools to address patients' social needs," with a Likert response scale ranging from strongly disagree to strongly agree (1 to 10$)$. We dichotomized responses at the median for responses in this national sample $(<6=$ low perceived clinic capacity; $\geq 6=$ high perceived clinic capacity).

\section{Covariates}

We included covariates that were both known to be associated with burnout and available in ABFM data, including patient-centered medical home (PCMH) status, percent vulnerable patient population (no definition was provided in the survey), race, ethnicity, gender, and years in practice; staffing support (having a social worker, pharmacist, behavior specialist, or psychiatrist); type of practice ("private practice," "hospital- or health maintenance organization [HMO]-based," or "federally qualified health center [FQHC] or similar"); practice size ("solo," "small [2 to 5 clinicians]," "medium [6 to 20 clinicians]," or "large $[20+$ clinicians]"); type of employment ("employee," "owner," or "contractor"); and being medical school and/or residency faculty ("no," "yes, parttime," "yes, full-time").

\section{Statistical Analysis}

Primary analyses focused on the association between perceived clinic SDH capacity and burnout, controlling for known burnout predictors. In a secondary analysis, we examined factors hypothesized to be associated with clinic SDH capacity and whether those factors mediated associations between clinic SDH capacity and burnout. Bivariate analyses between the covariates and the primary outcome (burnout) were performed to assess unadjusted associations $\left(\chi^{2}\right.$ and bivariate logistic regression). Multivariable logistic regression analyses were performed to control for covariates based on physician burnout literature. Interaction terms between covariates and the clinic SDH capacity variable assessed for a possible buffering or exacerbation of the association with burnout.
To evaluate the individual- and clinic-level characteristics associated with clinic SDH capacity, we conducted bivariate and multivariable logistic regression analyses by using the predictor variables hypothesized to contribute to clinic SDH capacity. To evaluate whether the factors associated with clinic SDH capacity were driving the association between clinic SDH capacity and burnout, the original multivariable logistic regression analysis for the outcome of burnout was repeated, controlling for the factors hypothesized to contribute to clinic SDH capacity. Interaction terms between covariates found to have a significant association with clinic SDH capacity and burnout were evaluated for effect modification on clinic SDH capacity.

The study was powered 0.80 or greater $(\alpha=$ $0.05,2$ sided) to detect an absolute difference of $7 \%$ in the primary binary outcome of burnout between groups reporting high and not high clinic SDH capacity. All data analyses were conducted using Stata/SE 15.0.

\section{Results}

Of 1298 family physicians responding to the burnout module in our sample, the mean age was 56 years, $44 \%$ were male, $72 \%$ were white, and mean years in practice was 19 (Table 2). Close to $90 \%$ reported having more than $50 \%$ direct patient care time. Eighty-two percent of respondents reported working in freestanding ambulatory clinics (vs hospital-based clinics); 59\% were in private practice, and $24 \%$ in hospital- or HMO-based clinics. Most worked in small (2 to 5 clinicians) or medium-sized (6 to 20 clinicians) practices (34\% and 35\%, respectively). Forty-three percent reported working in a recognized $\mathrm{PCMH} ; 43 \%$ reported that more than $20 \%$ or more of their patients were members of vulnerable populations.

Internal ABFM analyses showed no differences in physician characteristics between the 5 modules. However, when comparing respondent characteristics for the full ABFM survey to only those included in our study sample, there were 2 differences. In the study sample, there was a higher percentage of males ( $44 \%$ vs $41 \%, P=.014$ ) and fewer physicians caring for large numbers of vulnerable patient populations $(43 \%$ with $>20 \%$ vulnerable patients vs $51 \%$ with $>20 \%$ vulnerable patients, $P<.001)$. 
Table 2. Respondent-Reported Physician and Practice Site Characteristics by Burnout and Perceived Clinic Social Determinants of Health Capacity Among 1298 Family Physicians Applying for Continuous Certification with the American Board of Family Medicine in 2016*

\begin{tabular}{|c|c|c|c|c|c|c|c|}
\hline \multirow[b]{2}{*}{ Variable } & \multirow[b]{2}{*}{$\begin{array}{c}\text { Total } \\
(\mathrm{N}=1298) \\
\mathrm{N}(\%)\end{array}$} & \multicolumn{3}{|c|}{ Burnout } & \multicolumn{3}{|c|}{ Clinic SDH Capacity } \\
\hline & & $\begin{array}{c}\text { Burned Out } \\
(\mathrm{N}=481) \\
\mathrm{N}(\%)\end{array}$ & $\begin{array}{l}\text { Not Burned Out } \\
(\mathrm{N}=1444) \\
\mathrm{N}(\%)\end{array}$ & $P$ Value & $\begin{array}{c}\text { High SDH } \\
\text { Capacity } \\
(\mathrm{N}=589) \\
\mathrm{N}(\%)\end{array}$ & $\begin{array}{c}\text { Not High SDH } \\
\text { Capacity } \\
(\mathrm{N}=709) \\
\mathrm{N}(\%)\end{array}$ & $\begin{array}{c}P \\
\text { Value }\end{array}$ \\
\hline \multicolumn{8}{|l|}{ Age (years) } \\
\hline$\leq 45$ & $336(25.9)$ & $103(29.3)$ & $233(24.6)$ & & $168(23.7)$ & $168(28.5)$ & \\
\hline $46-55$ & $518(39.9)$ & $141(40.2)$ & $377(39.8)$ & & $232(40.3)$ & $286(39.4)$ & \\
\hline$\geq 56$ & $444(34.2)$ & $107(30.5)$ & $337(35.6)$ & .12 & $189(36.0)$ & $255(32.1)$ & .11 \\
\hline \multicolumn{8}{|l|}{ Sex $\dagger$} \\
\hline Male & $573(44.1)$ & $175(49.9)$ & $398(42.0)$ & & $264(44.8)$ & $325(43.6)$ & \\
\hline Female & $725(55.9)$ & $176(50.1)$ & $549(58.0)$ & $.012^{\ddagger}$ & $325(55.2)$ & $400(56.4)$ & .65 \\
\hline \multicolumn{8}{|l|}{ Years in Practice } \\
\hline$\leq 13$ & $3137(32.7)$ & $120(34.2)$ & $305(32.2)$ & & $223(37.9)$ & $202(28.5)$ & \\
\hline $14-21$ & $2989(32.1)$ & $120(34.2)$ & $297(31.4)$ & & $185(31.4)$ & $232(32.7)$ & \\
\hline$\geq 22$ & $3449(35.1)$ & $111(31.6)$ & $345(36.4)$ & .27 & $181(30.7)$ & $275(38.8)$ & $.0010^{\ddagger}$ \\
\hline \multicolumn{8}{|l|}{ Race } \\
\hline White & $931(71.73)$ & $265(75.5)$ & $666(70.3)$ & & $386(65.5)$ & $545(76.9)$ & \\
\hline Non-white & $367(28.3)$ & $86(24.5)$ & $281(29.7)$ & .066 & $203(34.5)$ & $164(23.1)$ & $<.0001^{\ddagger}$ \\
\hline \multicolumn{8}{|l|}{ Ethnicity } \\
\hline Hispanic & $78(6.01)$ & $13(3.7)$ & $65(6.9)$ & & $40(6.8)$ & $38(5.4)$ & \\
\hline Non-Hispanic & $1220(94.0)$ & $338(96.3)$ & $882(93.1)$ & $.033^{\dagger}$ & $549(93.2)$ & $671(94.6)$ & .28 \\
\hline \multicolumn{8}{|l|}{$\begin{array}{l}\% \text { Direct patient } \\
\text { care: }\end{array}$} \\
\hline$\leq 50 \%$ & $139(10.7)$ & $33(9.4)$ & $106(11.2)$ & & $71(12.1)$ & $68(9.6)$ & \\
\hline $51 \%-79 \%$ & $91(7.0)$ & $31(8.8)$ & $60(6.3)$ & & $42(7.13)$ & $49(6.9)$ & \\
\hline$\geq 80 \%$ & $1068(82.3)$ & $287(81.8)$ & $781(82.5)$ & .22 & $476(80.8)$ & $592(83.5)$ & .35 \\
\hline \multicolumn{8}{|l|}{ Workload control } \\
\hline Poor & $74(5.7)$ & $58(16.5)$ & $16(1.7)$ & & $35(5.9)$ & $39(5.5)$ & \\
\hline Marginal & $295(22.7)$ & $159(45.3)$ & $136(14.4)$ & & $108(18.3)$ & $187(26.4)$ & \\
\hline Satisfactory & $485(37.4)$ & $104(29.6)$ & $381(40.2)$ & & $212(36.0)$ & $273(38.5)$ & \\
\hline Good & $349(26.9)$ & $26(7.4)$ & $323(34.1)$ & & $180(30.6)$ & $169(23.8)$ & \\
\hline Optimal & $95(7.3)$ & $4(1.1)$ & $91(9.6)$ & $<.0001^{\ddagger}$ & $54(9.17)$ & $41(5.8)$ & $<.0001^{\ddagger}$ \\
\hline \multicolumn{8}{|l|}{ Team efficiency } \\
\hline Poor/Marginal & $104(8.0)$ & $62(17.7)$ & $42(4.4)$ & & $33(5.6)$ & $71(10.0)$ & \\
\hline Satisfactory & $306(23.6)$ & $114(32.5)$ & $192(20.3)$ & & $106(18.0)$ & $200(28.2)$ & \\
\hline Good & $712(54.9)$ & $151(43.0)$ & $561(59.2)$ & & $353(59.9)$ & $359(50.6)$ & \\
\hline Optimal & $176(13.6)$ & $24(6.84)$ & $152(16.1)$ & $<.0001^{\ddagger}$ & $97(16.5)$ & $79(11.1)$ & $<.0001^{\ddagger}$ \\
\hline \multicolumn{8}{|l|}{ Home EHR time } \\
\hline Excessive & $284(21.9)$ & $141(40.2)$ & $143(15.1)$ & & $99(16.8)$ & $185(26.1)$ & \\
\hline Moderate & $385(29.7)$ & $103(29.3)$ & $282(29.8)$ & & $187(31.8)$ & $198(27.9)$ & \\
\hline Satisfactory & $225(17.3)$ & $33(9.4)$ & $192(20.3)$ & & $111(18.9)$ & $114(16.1)$ & \\
\hline Modest & $170(13.1)$ & $32(9.1)$ & $138(14.6)$ & & $82(13.9)$ & $88(12.4)$ & \\
\hline Minimal/None & $234(18.0)$ & $42(12.0)$ & $192(20.3)$ & $<.0001^{\ddagger}$ & $110(18.7)$ & $124(17.5)$ & $.0020^{\ddagger}$ \\
\hline \multicolumn{8}{|l|}{ EHR proficiency } \\
\hline Poor/Marginal & $79(6.1)$ & $31(8.8)$ & $48(5.1)$ & & $29(4.9)$ & $50(7.1)$ & \\
\hline Satisfactory & $336(25.9)$ & $87(24.8)$ & $249(26.3)$ & & $132(22.4)$ & $204(28.8)$ & \\
\hline Good & $653(50.3)$ & $176(50.1)$ & $477(50.4)$ & & $310(52.6)$ & $343(48.4)$ & \\
\hline Optimal & $230(17.7)$ & $57(16.2)$ & $173(18.3)$ & .079 & $118(20.0)$ & $112(15.8)$ & $.0080^{\ddagger}$ \\
\hline
\end{tabular}




\begin{tabular}{|c|c|c|c|c|c|c|c|}
\hline \multirow[b]{2}{*}{ Variable } & \multirow[b]{2}{*}{$\begin{array}{c}\text { Total } \\
(\mathrm{N}=1298) \\
\mathrm{N}(\%)\end{array}$} & \multicolumn{3}{|c|}{ Burnout } & \multicolumn{3}{|c|}{ Clinic SDH Capacity } \\
\hline & & $\begin{array}{l}\text { Burned Out } \\
\begin{array}{c}(\mathrm{N}=481) \\
\mathrm{N}(\%)\end{array}\end{array}$ & $\begin{array}{l}\text { Not Burned Out } \\
(\mathrm{N}=1444) \\
\mathrm{N}(\%)\end{array}$ & $P$ Value & $\begin{array}{c}\text { High SDH } \\
\text { Capacity } \\
(\mathrm{N}=589) \\
\mathrm{N}(\%)\end{array}$ & $\begin{array}{c}\text { Not High SDH } \\
\text { Capacity } \\
(\mathrm{N}=709) \\
\mathrm{N}(\%)\end{array}$ & $\begin{array}{c}P \\
\text { Value }\end{array}$ \\
\hline \multicolumn{8}{|l|}{$\begin{array}{c}\text { Primary practice } \\
\text { ownership }\end{array}$} \\
\hline Private & $767(59.1)$ & $201(57.3)$ & $566(59.8)$ & & $304(51.6)$ & $463(65.3)$ & \\
\hline $\begin{array}{l}\text { Hospital or } \\
\text { HMO based }\end{array}$ & $309(23.8)$ & $84(23.9)$ & $225(23.8)$ & & $142(24.1)$ & $167(23.6)$ & \\
\hline $\begin{array}{l}\mathrm{FQHC} \text { and } \\
\text { similar }\end{array}$ & $136(10.5)$ & $40(11.4)$ & $96(10.1)$ & & $81(13.8)$ & $55(7.8)$ & \\
\hline Other & $86(6.6)$ & $26(7.4)$ & $60(6.3)$ & .78 & $62(10.5)$ & $24(3.4)$ & $<.0001^{\ddagger}$ \\
\hline $\begin{array}{l}\text { Pharmacist on } \\
\text { staff }\end{array}$ & $255(19.7)$ & $75(21.4)$ & $180(19.0)$ & .34 & $175(29.7)$ & $80(11.3)$ & $<.0001^{\ddagger}$ \\
\hline $\begin{array}{l}\text { Social work on } \\
\text { staff }\end{array}$ & $241(18.6)$ & $67(19.1)$ & $174(18.4)$ & .77 & $173(29.4)$ & $68(9.6)$ & $<.0001^{\ddagger}$ \\
\hline $\begin{array}{l}\text { Behavior specialist } \\
\text { on staff }\end{array}$ & $300(23.1)$ & $92(26.2)$ & $208(22.0)$ & .11 & $191(32.4)$ & $109(15.4)$ & $<.0001^{\ddagger}$ \\
\hline $\begin{array}{l}\text { Psychiatrist on } \\
\text { staff }\end{array}$ & $142(10.9)$ & $44(12.5)$ & $98(10.4)$ & .26 & $100(45.4)$ & $42(5.9)$ & $<.0001^{\ddagger}$ \\
\hline \multicolumn{8}{|l|}{ PCMH stage } \\
\hline Not applying & $435(33.5)$ & $113(32.2)$ & $322(34.0)$ & & $171(29.0)$ & $264(37.2)$ & \\
\hline Applying & $299(23.0)$ & $80(22.8)$ & $219(23.1)$ & & $110(18.7)$ & $189(26.7)$ & \\
\hline Recognized & $564(43.5)$ & $158(45.0)$ & $406(42.9)$ & .77 & $308(52.3)$ & $256(36.1)$ & $<.0001^{\ddagger}$ \\
\hline \multicolumn{8}{|l|}{$\begin{array}{c}\text { Vulnerable patient } \\
\text { population } \dagger\end{array}$} \\
\hline$<10 \%$ & $395(30.4)$ & $93(26.5)$ & $302(31.9)$ & & $168(28.5)$ & $227(32.0)$ & \\
\hline $10 \%-19 \%$ & $343(26.4)$ & $101(28.8)$ & $242(25.6)$ & & $137(23.3)$ & $206(29.1)$ & \\
\hline$\geq 20 \%$ & $560(43.1)$ & $157(44.7)$ & $403(42.6)$ & .16 & $284(48.2)$ & $276(38.9)$ & $.0030^{\ddagger}$ \\
\hline
\end{tabular}

*See Appendix Table 1 for full results of respondent characteristics.

${ }^{\dagger} P<.05$ for differences between full sample and study sample.

${ }^{\ddagger} P<.05$.

EHR, electronic health record; HMO, health maintenance organization; FQHC, federally qualified health center; SDH, social determinants of health; PCMH, patient-centered medical home.

\section{Association between Perceived Clinic Capacity to Address Patients' Social Needs and Burnout}

Twenty-seven percent of respondents reported burned out symptoms, similar to the $25 \%$ reported in a recent study using a less restricted sample of these same respondents. ${ }^{21}$ In unadjusted analyses, respondents who reported high clinic capacity to address patients' social needs had lower odds of burnout than those reporting lower capacity to address patients' social needs (odds ratio [OR], $0.58 ; 95 \%$ confidence interval [CI], 0.45-0.74) (Table 3). In multivariable analysis, the inverse association between clinic SDH capacity and burnout remained significant (OR, 0.71; 95\% CI, 0.520.98). Among the covariates, high workload control, high team efficiency, and minimal time documenting in the EHR at home were also significant predictors of burnout in the multivariable model.
In additional analyses conducted to account for factors hypothesized to contribute to clinic SDH capacity, the inverse association between burnout and clinic SDH capacity remained statistically significant (OR, 0.66; 95\% CI, 0.47-0.91), as did inverse associations between burnout and high workload control, high team efficiency, and minimal time documenting in the EHR. There were no statistically significant interactions between perceived clinic SDH capacity and other covariates in predicting burnout, including no significant interaction between SDH capacity and proportion of vulnerable patients in the practice in predicting the outcome of burnout. Reported levels of burnout, by level of clinic SDH capacity and stratified by vulnerable patient population, were similar for respondents working in practices with less than $20 \%$ and $20 \%$ or higher vulnerable patients $(P=.29)$, with a 
Table 3. Unadjusted and Adjusted Association between Clinic Social Determinants of Health Capacity and SelfReported Burnout among 1298 Family Physicians Applying for Continuous Certification with the American Board of Family Medicine in 2016*

\begin{tabular}{|c|c|c|c|c|c|c|c|c|}
\hline \multirow{2}{*}{$\begin{array}{l}\text { Perceived Clinic } \\
\text { SDH Capacity }\end{array}$} & \multicolumn{2}{|c|}{$\begin{array}{l}\text { Total Family } \\
\text { Physicians }\end{array}$} & \multicolumn{2}{|c|}{$\begin{array}{c}\text { Bivariate: Self- } \\
\text { Reported Burnout } \\
\mathrm{n} / \mathrm{N}=351 / 1298 \\
(27.0 \%)\end{array}$} & \multicolumn{2}{|c|}{$\begin{array}{c}\text { Multivariable Model } \\
\text { 1: }{ }^{\dagger} \text { Self-Reported } \\
\text { Burnout }\end{array}$} & \multicolumn{2}{|c|}{$\begin{array}{c}\text { Multivariable Model } \\
\text { 2: Self-Reported } \\
\text { Burnout }\end{array}$} \\
\hline & $\mathrm{N}=1298$ & $\%$ & OR & $95 \%$ CI & OR & $95 \% \mathrm{CI}$ & OR & $95 \%$ CI \\
\hline Low $(<6)$ & 709 & 54.6 & Ref & Ref & Ref & Ref & Ref & Ref \\
\hline $\operatorname{High}(>6)$ & 589 & 45.4 & $0.58^{\S}$ & $0.45-0.74$ & $0.71^{\S}$ & $0.52-0.98$ & $0.66^{\S}$ & $0.47-0.91$ \\
\hline
\end{tabular}

*See Appendix Table 2 for full results of regression models.

${ }^{\dagger}$ Variables controlled for include \% direct patient care, control of workload, team work efficiency EHR time at home, EHR proficiency, stage of PCMH, years in practice, sex, race, ethnicity, and \% vulnerable patient population.

${ }^{\ddagger}$ Variables controlled for include variables in model 1 , in addition to practice size, practice ownership, medical school faculty, residency faculty, presence of ancillary staff (pharmacist, social worker, behavior specialist, psychologist), and employment type. ${ }^{\circledR} P<.05$.

$\mathrm{SDH}$, social determinants of health; OR, odds ratio; CI, confidence interval; Ref, reference.

nonsignificant trend toward high clinic SDH capacity having a greater buffering effect on burnout for physicians working with a higher number of vulnerable patients [Insert Figure 1].

\section{Factors Associated with Perceived Clinic Capacity to Address Patients' Social Needs}

In unadjusted analyses, high clinic SDH capacity was more likely to be reported by respondents working at a recognized PCMH $(\mathrm{OR}, 1.86 ; 95 \%$ CI, 1.44-2.39), a clinic with 20 or more clinicians (OR, 2.03; 95\% CI, 1.37-3.02), at an FQHC or similar type practice (OR, 2.24; 95\% CI, 1.553.25 ), having over $20 \%$ vulnerable patients (OR, $1.39 ; 95 \% \mathrm{CI}, 1.07-1.80)$, and by those working in clinics with a social worker (OR, 3.92; 95\% CI, 2.89-5.33), a pharmacist (OR, 3.32; 95\% CI, $2.48-$ 4.45), behavior specialist (OR, 2.64; 95\% CI, 2.02 $3.45)$, or psychiatrist (OR, 3.25; 95\% CI, 2.224.74). These associations remained statistically significant only for working at a recognized PCMH $(\mathrm{OR}, 1.65 ; 95 \% \mathrm{CI}, 1.34-2.21)$ and working in clinics with a social worker $(\mathrm{OR}, 2.16 ; 95 \% \mathrm{CI}$, $1.44-3.26$ ) or pharmacist (OR, 1.73; 95\% CI,

Figure 1. Percentage of family medicine physicians applying for continuous certification with the American Board of Family Medicine in 2016 reporting burn out $(n=351)$, by level of clinic capacity to address patient's social needs (clinic social determinants of health $[\mathrm{SDH}]$ capacity), stratified by vulnerable patient population ( $z$ statistic, $-0.55, P=.29)$.

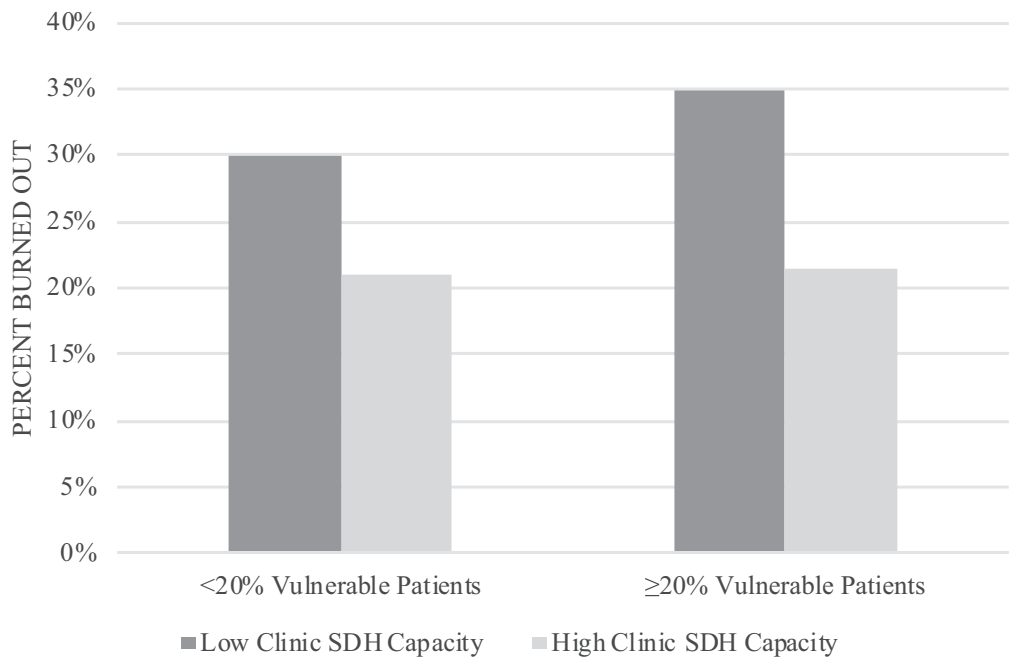

74 JABFM January-February 2019 Vol. 32 No. 1 
1.18-2.53), when adjusted for other factors expected to increase clinic SDH capacity (Table 4). None of the factors associated with perceived clinic SDH capacity were themselves associated with burnout (Appendix Table 2). There were no statistically significant interactions between burnout and the factors with significant associations with clinic SDH capacity in predicting clinic SDH capacity.

\section{Discussion}

This cross-sectional study is the first to include a national sample of family physicians to explore the relationship between physicians' perception of their clinic's ability to address patients' social needs and physician burnout. Given the rapidly expanding interest in ways that the health care sector can engage around $\mathrm{SDH},{ }^{22-25}$ this study provides important insights into how clinic resources to address social determinants may affect physician wellbeing.

We found a modest but statistically significant inverse association between perceived clinic capacity to address patients' social needs and burnout. Those reporting a high ability to meet patients' social needs had lower rates of burnout. The association remained significant when adjusting for other factors associated with both burnout and clinic SDH capacity and was true regardless of the percent vulnerable populations served. The inverse association between burnout and clinic SDH capacity was as strong as that between self-reported EHR proficiency and burnout. These findings are consistent with those found in an earlier study of primary care clinicians in San Francisco, CA, ${ }^{18}$ and with other work describing associations between physician stress and a lack of patient and organization resources. ${ }^{14}$ This study replicates that earlier work in a larger, national sample, and controls for a wider range of burnout risk factors.

Three practice-level factors were independently associated with physician perception of high clinic SDH capacity: reported presence of a social worker or pharmacist and working in a PCMH. Although these factors were not themselves significantly associated with burnout, association with clinic SDH capacity suggests that they likely influence physicians' work experiences. It is not surprising that physicians who reported having a social worker on staff would report higher capacity to assist patients with social needs. Having a pharmacist can also be instrumental in care coordination, ${ }^{26,27}$ medication refills and reconciliations, and patient education, all which may be particularly challenging for patients with social complexity. Alternatively, they may free up time for busy clinicians or other staff to more directly attend to patients' social needs. The association between PCMH status and clinic SDH capacity is consistent with $\mathrm{PCMH}$ criteria that recognize clinics that provide community resources and linkages to assist patients with health-related social needs. ${ }^{28}$ These 3 factors, social work and pharmacy availability and PCMH recognition, offer concrete policy or intervention targets for health systems seeking to increase clinic SDH capacity, which may, in turn, contribute to decreased burnout.

In contrast to our original hypothesis, the association between burnout and clinic capacity to address social needs was not limited to physicians working in safety-net practices and caring for relatively high proportions of vulnerable patients. $\mathrm{Al}$ though there was a trend toward higher burnout in physicians reporting to work at clinics with lower clinic SDH capacity and higher numbers of vulnerable patients, and high clinic SDH capacity appeared to have a greater buffering effect on burnout for physicians working with higher numbers of vulnerable patients, and these findings were not significant. It may be that social needs are ubiquitous among many types of patients or that physicians experience stress from the demands of caring for socially complex patients even when relatively few patients have social needs. Alternatively, although patients seen in safety-net settings are likely to have higher social service needs, physicians working in those settings may have more training and awareness about how to address patients' social needs than physicians working in other settings.

\section{Study Limitations}

The study had 3 important limitations. First, the cross-sectional design cannot indicate causality or directionality between clinic SDH capacity and burnout. Greater clinic SDH capacity may protect against physician burnout, but it is also possible that burnout causes physicians to have negative subjective ratings of their workplace, including their perception of clinic SDH capacity. We did test for interactions between burnout and factors associated with clinic SDH capacity (such as availability of social work, onsite pharmacy, and PCMH 
Table 4. Bivariate and Multivariable Logistic Analyses between Practice and Physician-Level Characteristics and Perceived Clinic Capacity to Address Patient's Social Needs Among 1298 Family Physicians Applying for Continuous Certification with the American Board of Family Medicine in 2016*

\begin{tabular}{|c|c|c|c|c|c|c|}
\hline \multirow[b]{2}{*}{ Variable } & \multicolumn{2}{|c|}{$\begin{array}{l}\text { Total Family } \\
\text { Physicians }\end{array}$} & \multicolumn{2}{|c|}{$\begin{array}{c}\text { Bivariate: High } \\
\text { Perceived Clinic } \\
\text { Capacity Clinic } \\
\text { Capacity, } \mathrm{n} / \mathrm{N}=589 / \\
1298(45.4 \%)\end{array}$} & \multicolumn{2}{|c|}{$\begin{array}{c}\text { Multivariable: }^{\dagger} \text { High } \\
\text { Perceived, } \mathrm{n} / \mathrm{N}=589 \\
1298(45.4 \%)\end{array}$} \\
\hline & $\mathrm{N}=1298$ & $\%$ & OR & $95 \% \mathrm{CI}$ & OR & $95 \% \mathrm{CI}$ \\
\hline \multicolumn{7}{|l|}{ Practice-level characteristics } \\
\hline \multicolumn{7}{|l|}{ Stage of PCMH } \\
\hline Not applying & 435 & 33.5 & Ref & Ref & Ref & Ref \\
\hline Applying & 299 & 23.0 & 0.90 & $0.66-1.22$ & 1.00 & $0.72-1.37$ \\
\hline Recognized & 564 & 43.5 & $1.86^{\ddagger}$ & $1.44-2.39$ & $1.65^{\ddagger}$ & $1.34-2.21$ \\
\hline \multicolumn{7}{|l|}{ Practice size } \\
\hline Solo & 184 & 14.2 & Ref & Ref & Ref & Ref \\
\hline Small (2-5 clinicians) & 439 & 33.8 & 0.97 & $0.68-1.34$ & 0.89 & $0.62-1.36$ \\
\hline Medium (6-20 clinicians) & 452 & 34.8 & 1.40 & $0.99-1.99$ & 1.00 & $0.60-1.37$ \\
\hline Large (20+ clinicians) & 222 & 17.1 & $2.03^{\ddagger}$ & $1.37-3.02$ & 1.08 & $0.51-1.41$ \\
\hline Other & 1 & 0.1 & 0.00 & 0.00 & 0.00 & 0.00 \\
\hline \multicolumn{7}{|l|}{ Practice ownership } \\
\hline Private practice & 767 & 59.1 & Ref & Ref & Ref & Ref \\
\hline Hospital or HMO based & 309 & 23.8 & 1.30 & $0.99-1.69$ & 0.95 & $0.68-1.32$ \\
\hline FQHC and similar & 136 & 10.5 & $2.24^{\ddagger}$ & $1.55-3.25$ & 1.35 & $0.86-2.14$ \\
\hline Other & 86 & 6.6 & $3.93^{\ddagger}$ & $2.40-6.44$ & $2.39^{\ddagger}$ & $1.35-4.24$ \\
\hline \multicolumn{7}{|l|}{ Medical school faculty } \\
\hline No & 996 & 76.7 & Ref & Ref & Ref & Ref \\
\hline Yes, Full time & 55 & 4.2 & 0.73 & $0.42-1.28$ & 0.55 & $0.27-1.13$ \\
\hline Yes, Part time & 247 & 19.0 & 0.98 & $0.74-1.30$ & 1.02 & $0.74-1.42$ \\
\hline \multicolumn{7}{|l|}{ Residency faculty } \\
\hline No & 1,122 & 86.4 & Ref & Ref & Ref & Ref \\
\hline Yes, full time & 70 & 5.4 & 0.91 & $0.56-1.48$ & 0.671 & $0.35-1.30$ \\
\hline Yes, part time & 106 & 8.2 & 1.12 & $0.752-1.67$ & 0.918 & $0.57-1.47$ \\
\hline \multicolumn{7}{|l|}{ Vulnerable patients } \\
\hline$<10 \%$ & 395 & 30.4 & Ref & Ref & Ref & Ref \\
\hline $10 \%-19 \%$ & 343 & 26.4 & 0.90 & $0.67-1.21$ & 0.96 & $0.70-1.31$ \\
\hline$\geq 20 \%$ & 560 & 43.1 & $1.39^{\ddagger}$ & $1.07-1.80$ & 1.10 & $0.82-1.48$ \\
\hline \multicolumn{7}{|l|}{ Pharmacist } \\
\hline No & 1,043 & 80.4 & Ref & Ref & Ref & Ref \\
\hline Yes & 255 & 19.7 & $3.32^{\ddagger}$ & $2.48-4.45$ & $1.73^{\ddagger}$ & $1.18-2.53$ \\
\hline \multicolumn{7}{|l|}{ Social work } \\
\hline No & 1,057 & 81.4 & Ref & Ref & Ref & Ref \\
\hline Yes & 241 & 18.6 & $3.92^{\ddagger}$ & $2.89-5.33$ & $2.16^{\ddagger}$ & $1.44-3.26$ \\
\hline \multicolumn{7}{|l|}{ Behavior specialist } \\
\hline No & 998 & 76.9 & Ref & Ref & Ref & Ref \\
\hline Yes & 300 & 23.1 & $2.64^{\ddagger}$ & $2.02-3.45$ & 1.28 & $0.88-1.87$ \\
\hline \multicolumn{7}{|l|}{ Psychiatrist } \\
\hline No & 1,156 & 89.1 & Ref & Ref & Ref & Ref \\
\hline Yes & 142 & 10.9 & $3.25^{\ddagger}$ & $2.22-4.74$ & 1.06 & $0.64-1.75$ \\
\hline
\end{tabular}

*See Appendix Table 3 for full results of regression models.

${ }^{\dagger}$ Variables controlled for include: years in practice, sex, race, ethnicity, employment type.

${ }^{\ddagger} P<.05$.

PCMH, patient-centered medical home; HMO, health maintenance organization; FQHC, federally qualified health center; OR, odds ratio; CI, confidence interval; Ref, reference. 
status) in predicting perceptions of clinic SDH capacity and found none. We believe this finding decreases the possibility that burnout is driving clinicians' perception of clinic SDH capacity. Experimental and longitudinal studies that increase either clinic SDH capacity or burnout resources would provide stronger evidence on causal relationships.

Second, the study relied on data collected during the ABFM continuing certification process, where few questions were asked about clinic attributes and resources. As a result, we are unable to assess other clinic resources that may contribute to clinic SDH capacity. The framing for the survey question about perceived clinic SDH capacity included examples such as "dedicated staff, community programs, resources or tools," to improve clarity, but the interpretation of social needs and clinic resources could have differed across respondents. ${ }^{29,30}$ The ability to compare reported responses to objectively measured clinic characteristics and resources would strengthen these findings.

Finally, the ABFM questionnaire did not define "vulnerable patients." This may have influenced our ability to detect an association between this variable and burnout or perceived clinic SDH capacity. Despite these limitations, our findings provide new insights into potential strategies to reduce physician burnout that could involve augmenting a clinic's capacity to address patients' social needs.

In conclusion, this study, using a large national survey of a representative sample of family physicians, found that physicians who perceive that their clinic has a greater capacity to address patients' social needs are less likely to report burnout. There is still more to learn about what shapes physicians' perceptions of clinic SDH capacity, how that capacity can change over time, and whether addressing it will be an effective strategy to prevent or to decrease burnout. As upstream interventions, including those focused on legal needs, food and housing security, or social support, become more prevalent in the US health care system, it will be useful to assess not only how those programs influence patient health, cost, and utilization but how they may affect physician burnout and retention.

The authors would like to thank Bo Fang, $\mathrm{PhD}$, for assisting with data extraction. An earlier version of this work was presented at the North American Primary Care Research Group, $45^{\text {th }}$ Annual Meeting, on November $20^{\text {th }} 2017$, in Montreal, Quebec.

To see this article online, please go to: http://jabfm.org/content/ 32/1/69.full.

\section{References}

1. Bodenheimer T, Sinsky C. From triple to quadruple aim: care of the patient requires care of the provider. Ann Fam Med 2014;12:573-6.

2. Shanafelt T, Goh J, Sinsky C. The business case for investing in physician well-being. JAMA Intern Med 2017;177:1826-1832.

3. Shanafelt TD, Hasan O, Dyrbye LN, et al. Changes in burnout and satisfaction with work-life balance in physicians and the general US working population between 2011 and 2014. Mayo Clin Proc 2015;90: 1600-13.

4. Dyrbye LN, Varkey P, Boone SL, Satele DV, Sloan JA, Shanafelt TD. Physician satisfaction and burnout at different career stages. Mayo Clin Proc 2013;88: $1358-67$.

5. Spinelli WM, Fernstrom KM, Galos DL, Britt HR. Extending our understanding of burnout and its associated factors: providers and staff in primary care clinics. Eval Health Prof 2016;39:282-98.

6. Willard-Grace R, Hessler D, Rogers E, Dube K, Bodenheimer T, Grumbach K. Team structure and culture are associated with lower burnout in primary care. J Am Board Fam Med 2014;27:229-38.

7. Rabatin J, Williams E, Baier Manwell L, Schwartz MD, Brown RL, Linzer M. Predictors and outcomes of burnout in primary care physicians. J Prim Care Community Health 2016;7:41-3.

8. McMurray JE, Linzer M, Konrad TR, Douglas J, Shugerman R, Nelson K. The work lives of women physicians: results from the physician work life study. J Gen Intern Med 2000;15:9.

9. Linzer M, Poplau S, Babbott S, et al. Worklife and wellness in academic general internal medicine: results from a national survey. J Gen Intern Med 2016; 31:1004-10.

10. Spinelli WM, Fernstrom KM, Britt HR, Pratt R. "Seeing the patient is the joy:". a focus group analysis of burnout in outpatient providers. Fam Med 2016; 48:6.

11. Ginossar T, Oetzel J, Hill R, Avila M, Archiopoli A, Wilcox B. HIV health-care providers' burnout: can organizational culture make a difference? AIDS Care 2014;26:1605-8.

12. Bronkhorst B, Tummers L, Steijn B, Vijverberg D. Organizational climate and employee mental health outcomes: a systematic review of studies in health care organizations. Health Care Manage Rev 2015; 40:254-71.

13. Shanafelt TD, Gorringe G, Menaker R, et al. Impact of organizational leadership on physician 
burnout and satisfaction. Mayo Clin Proc 2015;90: 432-40.

14. Hayashi AS, Selia E, McDonnell K. Stress and provider retention in underserved communities. J Health Care Poor Underserved 2009;20:597604.

15. Lewis SE, Nocon RS, Tang H, et al. Patient-centered medical home charcteristics and staff morale in safety net clinics. Arch Intern Med 2012;172:9.

16. Graber JE, Huang ES, Drum ML, et al. Predicting changes in staff morale and burnout at community health centers participating in the health disparities collaboratives. Health Serv Res 2008;43:1403-23.

17. Friedberg MW, Reid RO, Timbie JW, et al. Federally qualified health center clinicians and staff increasingly dissatisfied with workplace conditions. Health Aff (Millwood) 2017;36:1469-75.

18. Olayiwola JN, Willard-Grace R, Dube K, et al. Higher perceived clinic capacity to address patients' social needs associated with lower burnout in primary care providers. J Health Care Poor Underserved 2018;29:15.

19. Rohland BM, Kruse GR, Rohrer JE. Validation of a single-item measure of burnout against the Maslach Burnout Inventory among physicians. Stress and Health 2004;20:75-9.

20. Dolan ED, Mohr D, Lempa M, et al. Using a single item to measure burnout in primary care staff: a psychometric evaluation. J Gen Intern Med 2015;30:582-7.

21. Rassolian M, Peterson LE, Fang B, et al. Workplace factors associated with burnout of family physicians. JAMA Intern Med 2017;177:1036-8.

22. Bachrach D, Lipson M, Pfister H, Wallis K. Addressing social determinants of health: the business case for provider investment. New York: The Commonwealth Fund; 2014.

23. Institute for Alternative Futures. Community health centers leveraging the social determinants of health. Alexandria, VA: Institute for Alternative Futures; 2012.

24. Hussein T, Collins M. The community cure for health care. Stanford Social Innovation Review. 2016 Jul 21.

25. Alley DE, Asomugha CN, Conway PH, Sanghavi DM. Accountable health communities-addressing social needs through Medicare and Medicaid. N Engl J Med 2016;374:8-11.

26. Nelson KM, Helfrich C, Sun H, et al. Implementation of the patient-centered medical home in the Veterans Health Administration: associations with patient satisfaction, quality of care, staff burnout, and hospital and emergency department use. JAMA Intern Med 2014;174:1350-8.

27. Reid RJ, Coleman K, Johnson EA, et al. The group health medical home at year two: cost savings, higher patient satisfaction, and less burnout for providers. Health Aff (Millwood) 2010;29:835-43.

28. Wong W, Anderson K, Dankwa-Mullan I, Simon MA, Vega WA. The patient-centered medical home: a path toward health equity? Washington DC: Institute of Medicine; 2012.

29. Billioux A, Verlander K, Anthony S, Alley D. Standardized screening for health-related social needs in clinical settings. The accountable health communities screening tool. National Academy of Medicine 2017:9.

30. Adler NE, Stead WW. Patients in context-EHR capture of social and behavioral determinants of health. N Engl J Med 2015;372:4. 